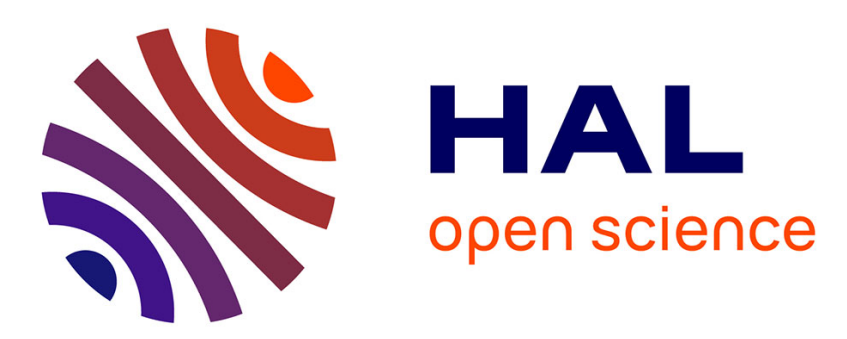

\title{
Structure, morphology and mechanical properties of electrodeposited composite coatings Niâ $\mathrm{P} / \mathrm{SiC}$
}

Joël Alexis, Bernard Etcheverry, Jean-Denis Béguin, Jean-Pierre Bonino

\section{To cite this version:}

Joël Alexis, Bernard Etcheverry, Jean-Denis Béguin, Jean-Pierre Bonino. Structure, morphology and mechanical properties of electrodeposited composite coatings Niâ P/SiC. Materials Chemistry and Physics, 2010, vol. 120, pp. 244-250. 10.1016/j.matchemphys.2009.12.013 . hal-00760126

\section{HAL Id: hal-00760126 \\ https://hal.science/hal-00760126}

Submitted on 4 Dec 2012

HAL is a multi-disciplinary open access archive for the deposit and dissemination of scientific research documents, whether they are published or not. The documents may come from teaching and research institutions in France or abroad, or from public or private research centers.
L'archive ouverte pluridisciplinaire HAL, est destinée au dépôt et à la diffusion de documents scientifiques de niveau recherche, publiés ou non, émanant des établissements d'enseignement et de recherche français ou étrangers, des laboratoires publics ou privés. 


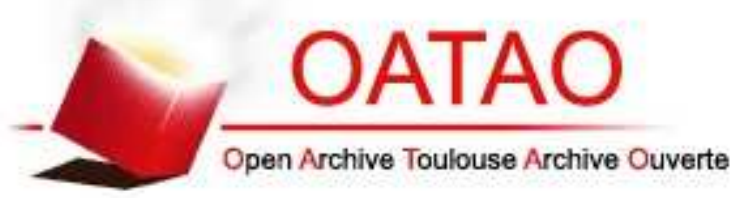

Open Archive Toulouse Archive Ouverte (OATAO)

OATAO is an open access repository that collects the work of Toulouse researchers and makes it freely available over the web where possible.

This is an author-deposited version published in: http://oatao.univ-toulouse.fr/ Eprints ID: 6487

To link to this article: DOI: $10.1016 /$ j.matchemphys.2009.12.013 http://dx.doi.org/10.1016/i.matchemphys.2009.12.013

\section{To cite this version:}

Alexis, Joël and Etcheverry, Bernard and Béguin, Jean-Denis and Bonino, JeanPierre Structure, morphology and mechanical properties of electrodeposited composite coatings $\mathrm{Ni} \square \mathrm{P} / \mathrm{SiC}$. (2010) Materials Chemistry and Physics, vol. 120 (n 2-3). pp. 244-250. ISSN 0254-0584

Any correspondence concerning this service should be sent to the repository administrator: staff-oatao@inp-toulouse.fr 


\title{
Structure, morphology and mechanical properties of electrodeposited composite coatings $\mathrm{Ni}-\mathrm{P} / \mathrm{SiC}$
}

\author{
J. Alexis ${ }^{\mathrm{a}, *}$, B. Etcheverry ${ }^{\mathrm{a}}$, J.D. Beguin ${ }^{\mathrm{a}}$, J.P. Bonino ${ }^{\mathrm{b}}$ \\ a Laboratoire Génie de Production, Ecole Nationale d'Ingénieurs de Tarbes, 47 av. d'Azereix, B.P. 1629, 65016 Tarbes Cedex, France \\ ${ }^{\mathrm{b}}$ CIRIMAT - CNRS (UMR n 5085), Université Paul Sabatier, 118 route de Narbonne, 31062 Toulouse Cedex 4, France
}

\begin{abstract}
A B S T R A C T
Physical properties of the $\mathrm{NiP} / \mathrm{SiC}$ deposits are discussed according to the electroplating parameters and heat treatments. The insertion of silicon carbide in the coatings does not modify their rigidity $(E=230 \mathrm{GPa})$, increases their hardness slightly (50 Vickers) and decreases the residual stresses in coatings.

The phosphorus content has a major effect on the structure and the physical properties. Indeed, insertion of phosphorus into the deposits generates a grain size reduction or even an amorphisation which results in morphological modifications observed by AFM. In parallel a very important hardening is associated with incorporation of phosphorus: hardness is multiplied by 3 to reach $600 \mathrm{HV} 0.1$.

The deposits tend to become crystalline following the heat treatments. With $420^{\circ} \mathrm{C}$, the precipitation of a $\mathrm{Ni}_{3} \mathrm{P}$ phase which distorts the crystal lattice is observed, increasing the hardness of the deposits.
\end{abstract}

Keywords:

Nickel-phosphorus

Coating

Mechanical properties

* Corresponding author. Tel.: +33 0562442759; fax: +33 0562442708

E-mail address: joel.alexis@enit.fr (J. Alexis). obtained are discussed according to their morphological and structural characteristics.

\section{Experimental details}

\section{Introduction}

To meet aims of eco-design and use clean technologies, excluding rejections from effluents containing chromium VI, a study on composite coatings $\mathrm{NiP} / \mathrm{SiC}$ were carried out in order to replace the hard chromium deposits. Indeed, even if no law prohibits the use of baths containing hexavalent chromium, a French ministerial decree (no. 2005-378: 20 April 2005) limits very strongly atmosphere and water pollution by fixing the concentration limits in the effluents at $0.1 \mathrm{mg} \mathrm{l}^{-1}$ and the content limits in gases and vapors rejected to $0.1 \mathrm{mg} \mathrm{mm}^{-3}$. The insertion of $\mathrm{SiC}$ particles should make it possible to increase the mechanical properties of the nickel coatings in order to obtain a hardness comparable with the hard chromium deposits $(1000 \mathrm{HV})$ [1-3]. The purpose of the undertaken study is to evaluate the mechanical properties of electrodeposited $\mathrm{NiP} / \mathrm{SiC}$ coatings. It is based on microhardness and nanohardness tests and analyses by X-ray diffraction in order to determine the nature of the crystalline phases present as well as the rate of internal stresses. To carry out the deposits, we varied the phosphorus and SiC content of the electrolyte and we carried out two post heat treatments: $190^{\circ} \mathrm{C}$ under air (amorphous state without residual stress) and $420^{\circ} \mathrm{C}$ (crystalline state) under nitrogen. The temperatures of treatment were selected according to the studies undertaken by others authors [4-6]. The mechanical properties of the various coatings
$\mathrm{NiP} / \mathrm{SiC}$ deposits were electrodeposited in a cell whose electrodes are static and vertical, containing $140 \mathrm{~cm}^{3}$ of electrolyte. The cathode is a copper disk substrate of surface $1.7 \mathrm{~cm}^{2}$. The anode was a high-purity nickel ingot with an effective area of $4 \mathrm{~cm}^{2}$. The substrates are pickled in a nitric bath of diluted acid and are rinsed with distilled water before deposition. SiC particles (99.9\% $\mathrm{SiC}$ ) come from NEYCO. It has an average diameter of $600 \mathrm{~nm}$. The various deposits are indicated $\mathrm{P}_{x} \mathrm{~S}_{y}$ thereafter with $x$ and $y$ respectively the phosphorous acid $\mathrm{H}_{3} \mathrm{PO}_{3}$ contents and the $\mathrm{SiC}$ content of the electrolyte.

The temperature of the bath as well as the current density is respectively fixed at $80^{\circ} \mathrm{C}$ and $10 \mathrm{Adm}^{-2}$. The $\mathrm{pH}$ is adjusted to 2 after introduction of $\mathrm{SiC}$ particles in suspension in the electrolyte. The bath was stirred by a rotative stirring rod to increase the SiC particles incorporation. Time was fixed to obtain $60 \mu \mathrm{m}$ thick deposits. Four series of samples were carried out by varying the content of $\mathrm{SiC}$ particles, the phosphorous acid of the electrolyte and the heat treatments at $190^{\circ} \mathrm{C}$ and $420^{\circ} \mathrm{C}$ (Table 1 ). The evolution of the phosphorus content as well as the $\mathrm{SiC}$ particles content in the deposits respectively to the phosphorus acid content and the $\mathrm{SiC}$ particles content of the electrolyte are presented in Fig. 1.

The topographic observations were carried out using the inductive feeler profilometer SURFASCAN 3D. Scanned surfaces have 
Table 1

Elaboration parameters of the coatings.

\begin{tabular}{|c|c|c|c|c|c|c|c|}
\hline \multirow[t]{2}{*}{ Series } & \multicolumn{6}{|c|}{ Composition of the bath } & \multirow[t]{2}{*}{ Post-treatment } \\
\hline & $\mathrm{NiSO}_{4} \cdot 6 \mathrm{H}_{2} \mathrm{O}$ & $\mathrm{NiCl}_{2} \cdot 6 \mathrm{H}_{2} \mathrm{O}$ & $\mathrm{H}_{3} \mathrm{PO}_{4}$ & $\mathrm{H}_{3} \mathrm{PO}_{3}$ & $\mathrm{Na}_{2} \mathrm{SO}_{4}$ & $\mathrm{SiC}$ & \\
\hline 1 & $210 \mathrm{gl}^{-1}$ & $60 \mathrm{gl}^{-1}$ & $50 \mathrm{gl}^{-1}$ & 0 & $50 \mathrm{gl}^{-1}$ & 0 to $80 \mathrm{~g} \mathrm{l}^{-1}$ & Untreated \\
\hline 2 & $210 \mathrm{gl}^{-1}$ & $60 \mathrm{gl}^{-1}$ & $50 \mathrm{gl}^{-1}$ & 0 to $20 \mathrm{gl}^{-1}$ & $50 \mathrm{gl}^{-1}$ & $20 \mathrm{gl}^{-1}$ & Untreated \\
\hline 3 & $210 \mathrm{gl}^{-1}$ & $60 \mathrm{gl}^{-1}$ & $50 \mathrm{gl}^{-1}$ & 0 to $20 \mathrm{~g} \mathrm{l}^{-1}$ & $50 \mathrm{gl}^{-1}$ & $20 \mathrm{gl}^{-1}$ & $190^{\circ} \mathrm{C}$ treated $3 \mathrm{~h}$-air \\
\hline 4 & $210 \mathrm{gl}^{-1}$ & $60 \mathrm{gl}^{-1}$ & $50 \mathrm{gl}^{-1}$ & 0 to $20 \mathrm{gl}^{-1}$ & $50 \mathrm{gl}^{-1}$ & $20 \mathrm{gl}^{-1}$ & $420^{\circ} \mathrm{C}$ treated $1 \mathrm{~h}$-nitrogen \\
\hline
\end{tabular}

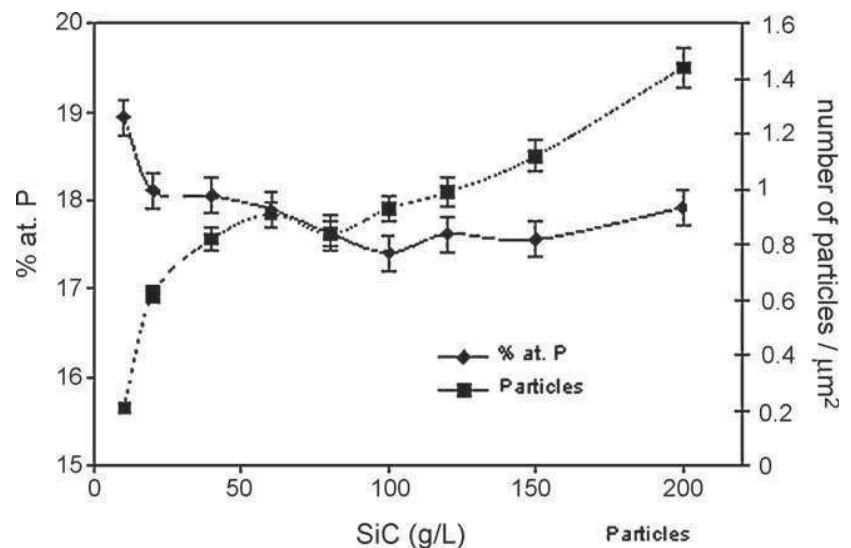

Fig. 1. Effect of SiC content particles of the electrolyte on the evolution of the average roughness $R_{a}$ and of the developed surface ratio $S d r$.

a $0.5 \mathrm{~mm} \times 0.5 \mathrm{~mm}$ dimension with an acquisition step of $2 \mu \mathrm{m}$ according to the two axes. The scanning electron microscope Philips SEM 515 coupled to analyses by spectrometry with energy Xdispersion well as the atomic force microscope NanoScope III made it possible to characterize the morphology of the deposits.

The whole of the analyses by X-ray diffraction was carried out on the diffractometer Philips MRD by using a copper anticathode $(\lambda=0.15415 \mathrm{~nm})$ in order to determine crystalline structure of the deposits in configuration $\theta-2 \theta$ and in addition their residual stress state according to the $\sin ^{2} \psi$ method.

The microhardness of the various deposits was determined by using the microdurometer Shimadzu HMV-2 under several loads from $25 \mathrm{~g}$ to $200 \mathrm{~g}$. The values given are the averages of the hardness's obtained thanks to a minimum of 5 tests for each load and each deposit. The maximum load was given according to the depth ratio of indentation depth/thickness of the deposits which is equal to a maximum of 0.09 in our case in order to remove the influence

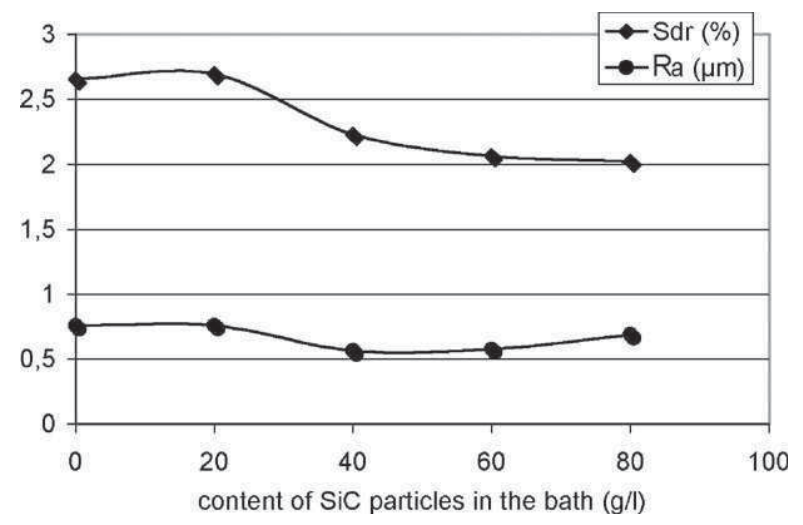

Fig. 2. Effect of SiC particles on the coatings morphologies (a) POS20 and (b) POS80.

of the copper substrate on the measurements. The nanohardness tests were carried with the nanoindentor XP from MTS. A matrix of 20 measurements in dynamic mode was carried out on the section of each deposit by imposing a maximum displacement of $500 \mathrm{~nm}$ in-depth. Spacing between each indent is of $9 \mu \mathrm{m}$ to avoid the phenomena of work hardening between each test. The Young's modulus of the deposits is calculated starting from the contact stiffness measured at the time of unloading [7]

$S e=\frac{d P}{d H}=\frac{2}{\sqrt{\pi}} E r \sqrt{A\left(h_{c}\right)}$

where Se the stiffness of contact determined in the higher part of the curve of discharge, $P$ the load applied, $H$ the indentation depth, $A$ $\left(h_{c}\right)$ the contact area function to indentation depth, $E r$ the effective module of the system holding account of the Young's moduli and the Poisson's ratios of indentor $\left(E_{i}, v_{i}\right)$ and of the sample $\left(E_{e}, v_{e}\right)$.

$\frac{1}{E_{r}}=\frac{1-v_{i}^{2}}{E_{i}}+\frac{1-v_{e}^{2}}{E_{e}}$

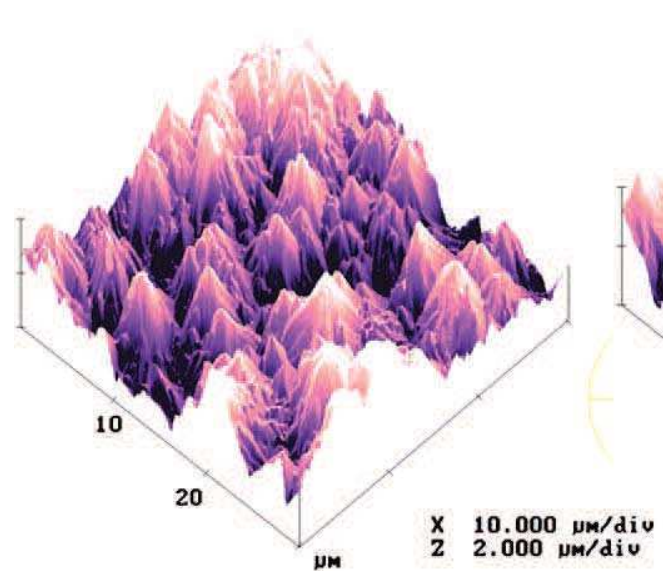

(a)

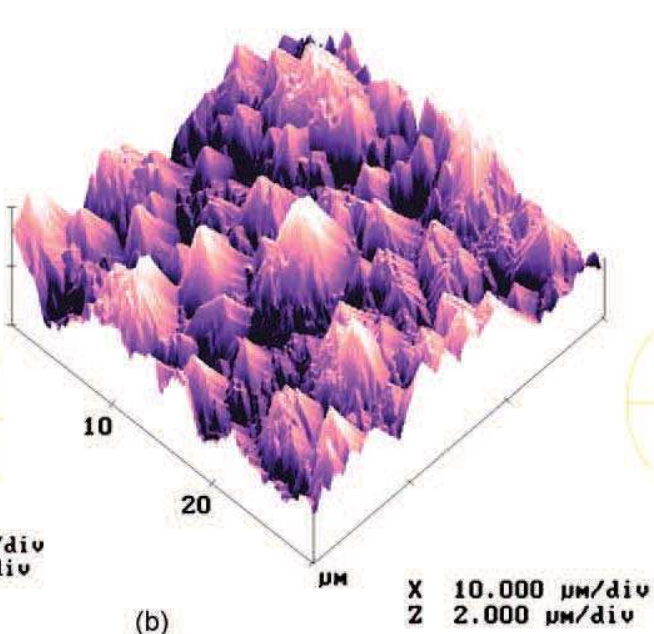

(b)
2 2.000 $\mathrm{nm} / \mathrm{div}$

Fig. 3. Effect of SiC content on the coatings' structure. 


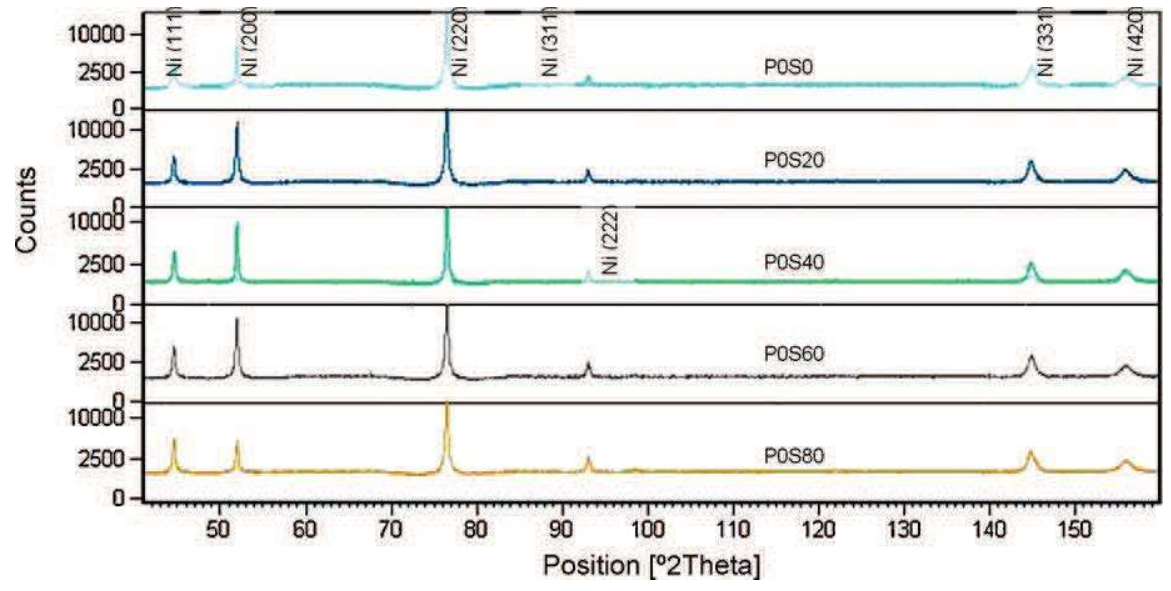

Fig. 4. Effect of $\mathrm{SiC}$ particles content of the bath on the deposits texture.

\section{Results}

\subsection{Influence of the SiC particles content}

The evolution of the average roughness $R_{a}$ and the ratio of surface developed/surface scanned Sdr according to the SiC content of the bath is presented Fig. 2. These two parameters decrease slightly then stabilize. This light levelling of the surface of the deposits corresponds to a microstructural refinement observed under the scanning electron microscope and the atomic force microscope. The pyramidal grains are denser and well cuts with a content of $\mathrm{SiC}$ increasing. The morphology is typical among that of crystalline deposits (Fig. 3). Moreover, with the increase in SiC content of the bath, phenomena of abrasion on the surface occurs during the elaboration, thus decreasing the roughness of the deposits.

The structure of the various coatings according to the SiC content of the electrolyte is presented Fig. 4. Taking into account the important thickness of the deposits $(60 \mu \mathrm{m})$, no peak of diffraction related to the copper substrate appears. Moreover, SiC is not detected whatever the deposit. Only the Ni phase corresponding to JCPDS card no. 04-0850 is highlighted.

All the diffraction diagrams present well defined and distinct peaks that confirm the crystallinity of the deposits. However, the intensity ratio for each measured peak is different from the intensity ratio of the JCPDS card. It could be due to a preferred crystalline

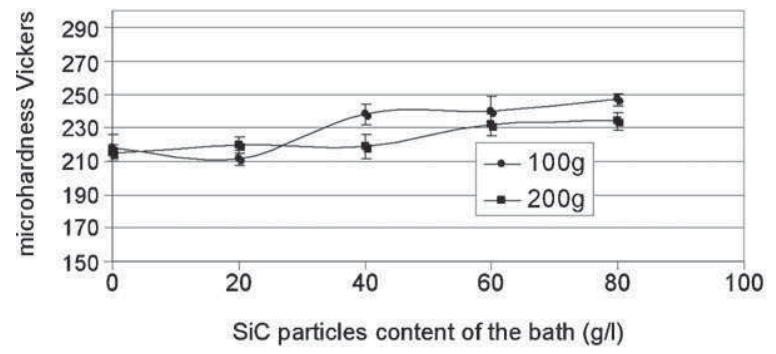

Fig. 6. Loading-unloading curves function to $\mathrm{SiC}$ particles content of the bath

orientation. The peak intensity corresponding to the family of plan (200) of Ni is more important than that of the peak of the family of plan (111) which should be most intense according to the JCPDS card. A comparative study of texture has been carried out on copper substrate and on deposits containing different percentage of $\mathrm{SiC}$ particles. Other electroplating conditions ( $\mathrm{pH}$, temperature, potential difference, etc.) are constant. As Fig. 5 shows, the pole figures of the plans (111) and (220) of the POSO deposit exhibit a typical $\langle 110\rangle$ texture fibre completely different from the brass texture of $\mathrm{Cu}$ substrate. Moreover, this fibre texture seems to be independent of SiC content particles contrary to what is observed by CHOU [8].

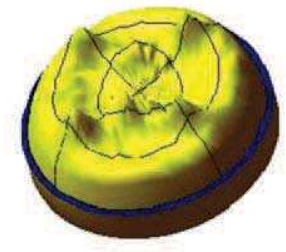

Typical «Brass texture » Copper (111)

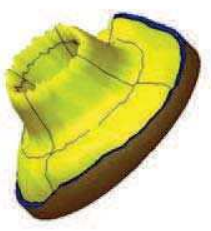

POSO (111)

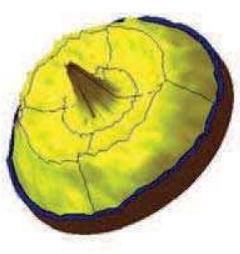

POSO (220)
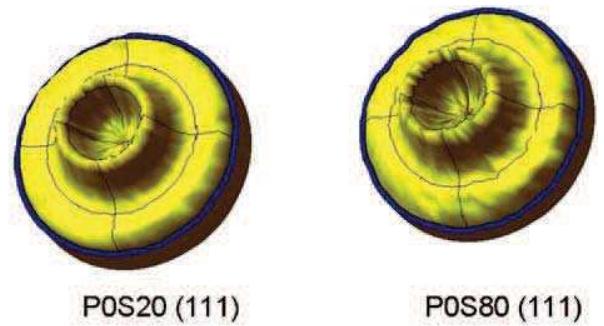

POS80 (111)
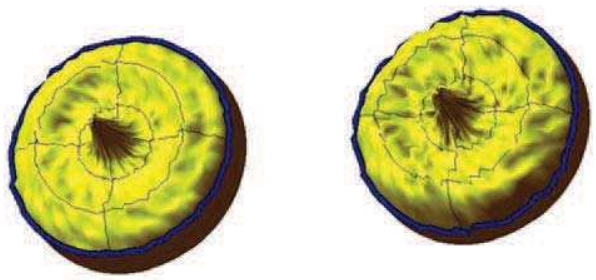

POS20 (220)

Fig. 5. Effect of $\mathrm{SiC}$ content of the bath on the microhardness function to the applied load. 


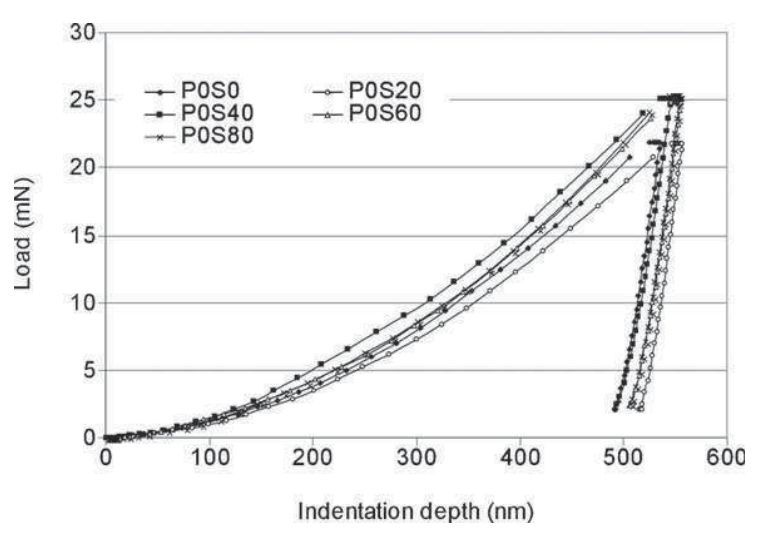

Fig. 7. Effect of SiC particles content of the bath on the nanohardness and the Young's modulus.

The microhardness tests carried out with $100 \mathrm{~g}$ and $200 \mathrm{~g}$ loads show in all cases a slight increase in the hardness of the deposits with the increase in SiC content of the bath (Fig. 6). The values found for pure $\mathrm{Ni}$ deposit are in conformity with those given by Dedeloudis et al. [2]. However, the increase rate in hardness measured by this author with the insertion of $\mathrm{SiC}$ particles is not confirmed by our measurements. This difference can be explained by the size of the inserted particles. Indeed, Dedeloudis uses particles of size $150 \mathrm{~nm}$ whereas those used for this study have a size around $660 \mathrm{~nm}$. The slight hardness increase in our case seems to be only induced by the intrinsic mechanical properties of the particles which have a high hardness and a high modulus of elasticity. Particles of very low size used by Dedeloudis et al. can take into account, as they showed, the dislocation movement; reinforcing more the nickel matrix.

Fig. 7 presents the evolution of the mechanical behaviour of the deposits according to the SiC content of the bath. All the deposits have a virtually identical behaviour; which seems to confirm the preceding observations: the particles of important size would not intercede on the mechanical behaviour of the matrix by blocking any dislocations in particular. They are characterized by a weak elastic return $(\cong 50 \mathrm{~nm})$. Moreover, the $\mathrm{SiC}$ content does not influence the Young modulus value of the deposits which is about 230 GPa (Fig. 8). Nanohardness also remains relatively stable even if a very slight increase for the deposits elaborated with an electrolyte containing $40 \mathrm{gl}^{-1}$ of SiC particles is observed. Moreover, the nanohardness tests do not highlight any hardness gradient in the thickness of the deposits. This result is to be attributed to the good $\mathrm{SiC}$ particles distribution observed in optical microscopy.

Lastly, the internal stresses were determined according to the $\sin ^{2} \psi$ method starting from the variations of the inter-reticular distances of the nickel plans $(420)\left(2 \theta=144.66^{\circ}\right)$. X-ray crystallographic constants of this plan family, used in the calculation of the stresses, are those given by Casteix et al. [9]: $S 1=-1.43 \times 10^{-6} \mathrm{MPa}$

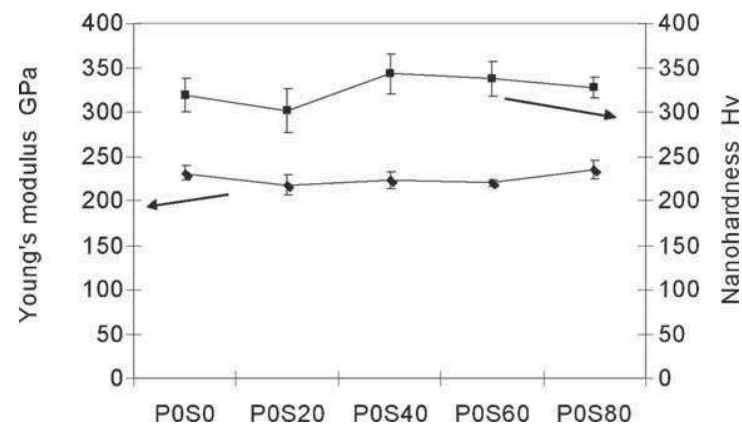

Fig. 8. Effect of the acid phosphorus content of the electrolyte on the roughness parameters.
Table 2

Effect of SiC particles content of the electrolyte on the residual stresses.

\begin{tabular}{lll}
\hline Coatings & Internal stresses (MPa) \\
\cline { 2 - 3 } & Average & Standard deviation \\
\hline POS0 & 136.6 & 13.8 \\
POS40 & 100 & 10 \\
POS80 & 55.3 & 7.4 \\
\hline
\end{tabular}

and $1 / 2 S 2=6.15 \times 10^{-6} \mathrm{MPa}$. In spite of the crystalline anisotropy highlighted previously, the good linearity of the curves $D=$ function $\left(\sin ^{2} \psi\right)$ allowed us to study the residual stresses comparatively. The results show that the coatings are in tension and the tensile stress decreases with the increase in $\mathrm{SiC}$ content in the electrolyte (Table 2). This confirms the results previously shown by Chou [8] and Berkh [1].

\subsection{Influence of the $\mathrm{H}_{3} \mathrm{PO}_{3}$ content}

The phosphorus content in the electrolyte very clearly influences the topography of the deposits. Indeed, as the joint reductions in average roughness $R_{a}$ and the ratio $S d r$ show, the coatings deposited in the presence of acid phosphorous are by far the least disturbed (Fig. 9) and this, just with the incorporation of $2 \mathrm{gl}^{-1}$ of $\mathrm{H}_{3} \mathrm{PO}_{3}$ in the bath.

This levelling according to the $\mathrm{H}_{3} \mathrm{PO}_{3}$ content of the bath is explained by a radical change of the morphology of the deposits. The coatings deposited without phosphorus are made up, as we have seen by pyramidal grains, characteristic of a crystalline structure whereas the deposits elaborated in the presence of $\mathrm{H}_{3} \mathrm{PO}_{3}$ have a globular morphology which would return rather to an amorphous structure (Fig. 10).

The X-ray diffraction analysis (Fig. 11) confirms the topographic and morphological changes between the coating deposited with or without phosphorus. The transition of the crystalline state towards a less ordered state is characterized by broader and less intense peaks which can continue until disappearing according to increasing phosphorus content. Thus, only deposits of P2S20 containing 7.67 at.\% of phosphorus are crystalline, even microcrystalline taking into account the extinction and the widening of the whole of the peaks compared to the POS20. On the sample without phosphorus, the smoothness of the peaks is the result of strong crystallinity of the deposit for this composition, as has been shown previously. On the other hand, the inversion of the intensities of the peaks (111) and (200) for sample P2S20 (7.67 at.\% of P) could be explained by a change of crystalline texture with the phosphorus incorporation: the deposit without phosphorus presents a preferential orientation of the (200) plan parallel to the surface whereas the P2S20 favours the plan (111). This result was already observed by Lewis and Marshall [10]. They assign this privileged orientation of the plans (111) with increasing phosphorus content in the deposits due to the fact that the deformations of the crystallites are more

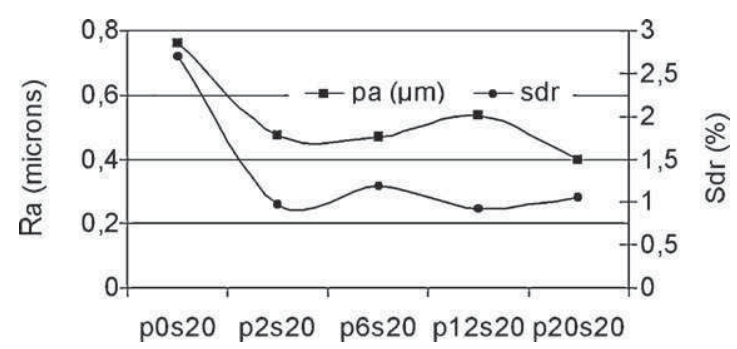

Fig. 9. Effect of the acid phosphorus content of the bath (a) POS20, (b) P6S20, and (c) P20S20 on the morphologies of the untreated samples obtained by atomic force microscopy. 

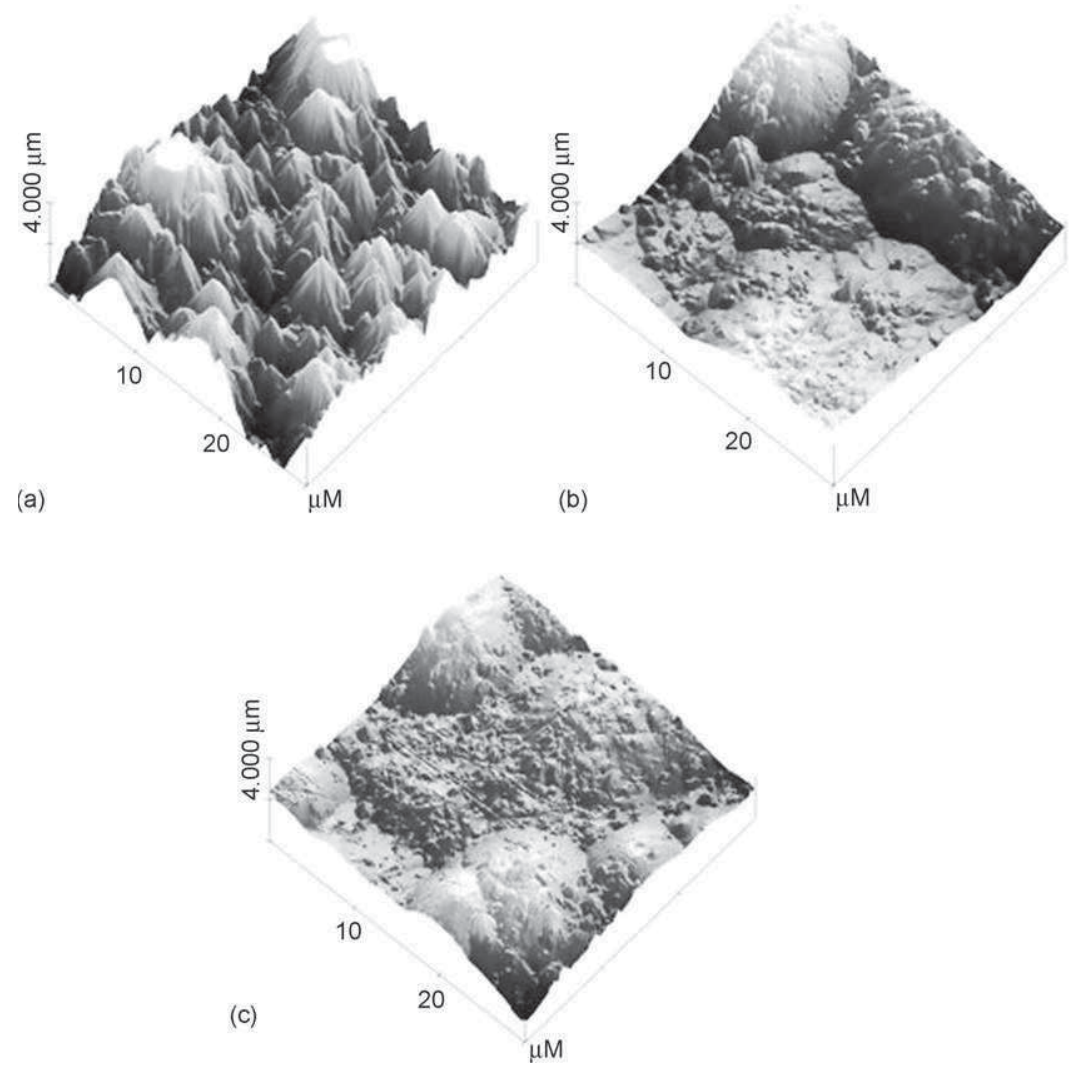

Fig. 10. Effect of the acid phosphorus content on the coatings' structure.

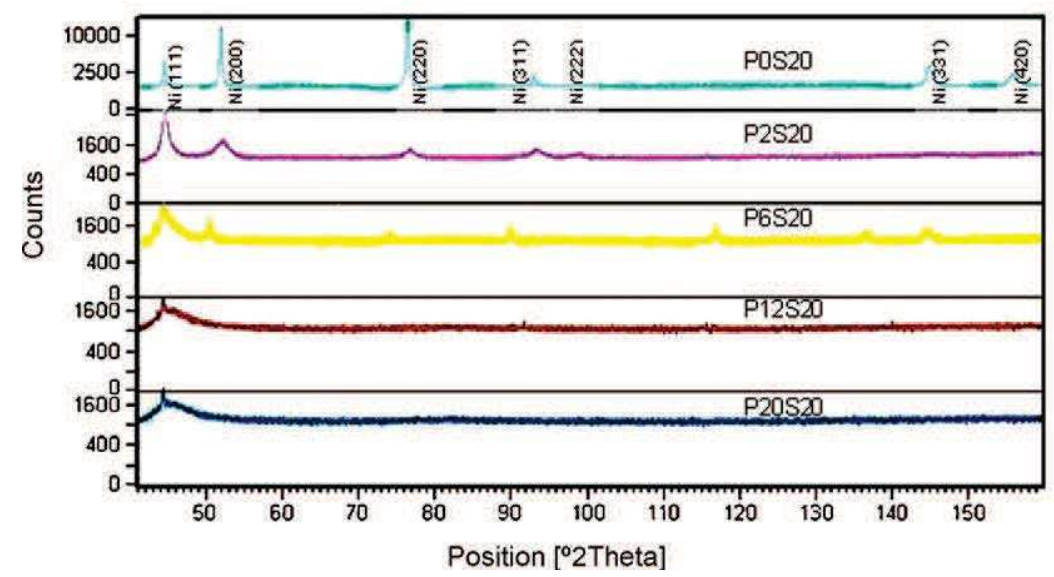

Fig. 11. Effect of acid phosphorus content of the bath on the microhardness function to the applied load.

important according to the crystalline plans $(200)$ than that of the plans ( 1111 ).

Beyond this content of 7.67 at.\% of phosphorus, that means for all the other samples, the coating becomes amorphous: the diffraction peaks decrease, widen then disappear. Phosphorus dissolves in solid solution in the nickel mesh and does not appear on the X-ray diffractograms.

The microhardness of the deposits evolves considerably according to the phosphorus content (Fig. 12). It is multiplied by a factor of 3 between coatings deposited without phosphorus and another elaborate with $2 \mathrm{~g} \mathrm{l}^{-1}$ in the bath to reach approximately $600 \mathrm{HV} 0.1$. This increase is in conformity with that measured by Yucheng [11] and Cheng [12] and lower than that measured by Apachitei [13]. A slight reduction in hardness is then observed for the high phos-

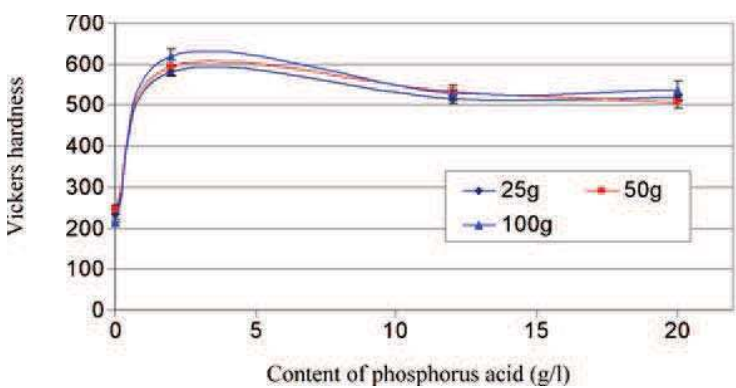

Fig. 12. Loading-unloading curves function to the acid phosphorus content. 


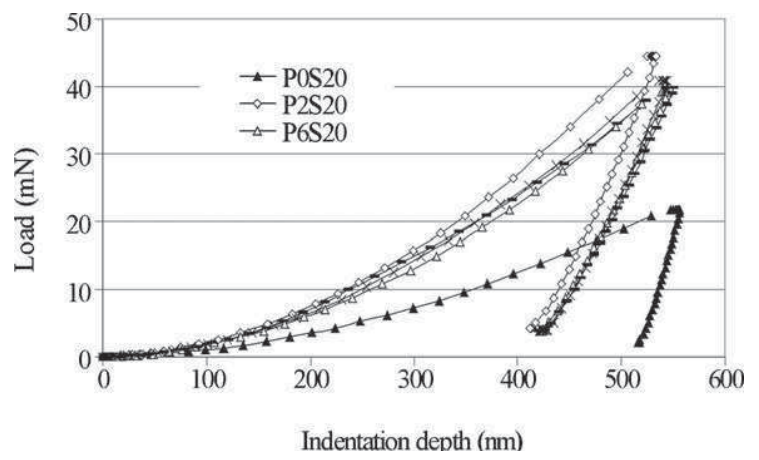

Fig. 13. Effect of the acid phosphorus content on the nanohardness and Young's modulus.

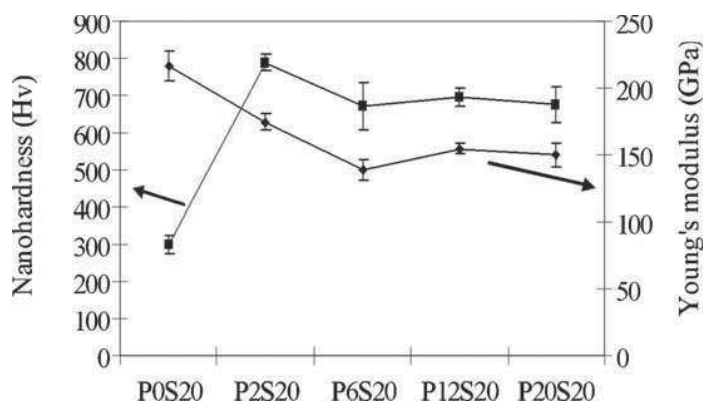

Fig. 14. Effect of heat treatments on the microhardness: (a) heat treatment at $190^{\circ} \mathrm{C}$ under air and (b) heat treatment at $420^{\circ} \mathrm{C}$ under nitrogen.

phorus contents of the bath. It is interesting to note that only these deposits tend to fissure with the Vickers tests carried out with a load of $100 \mathrm{~g}$. This can be due to a change of mechanical behaviour; and more particularly to the increased brittleness of the deposits rich in phosphorus. The modifications of the mechanical behaviour with the insertion of phosphorus in the Ni matrix are confirmed by the shape of the loading and unloading curves obtained during nanoindentation tests (Fig. 13). The deposits containing phosphorus are characterized by an elastic return three times larger than the deposit without phosphorus. Moreover, as Weaire [14] underlines it, a reduction of $30 \%$ of the value of the Young's modulus is observed for the amorphous deposits (Fig. 14). This fall is explained by local rearrangements within the disordered structure of amorphous alloy under a given pressure $[15,16]$.

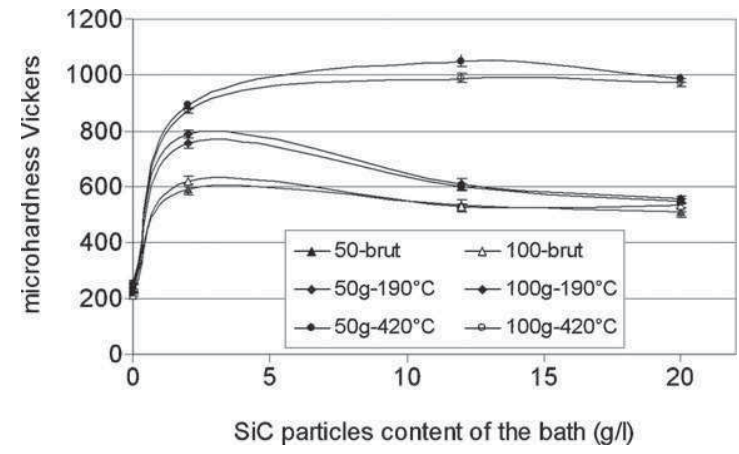

Fig. 15. Effect of heat treatments on the deposits nanohardness: heat treatment at $190{ }^{\circ} \mathrm{C}$ under air and heat treatment at $420^{\circ} \mathrm{C}$ under nitrogen.

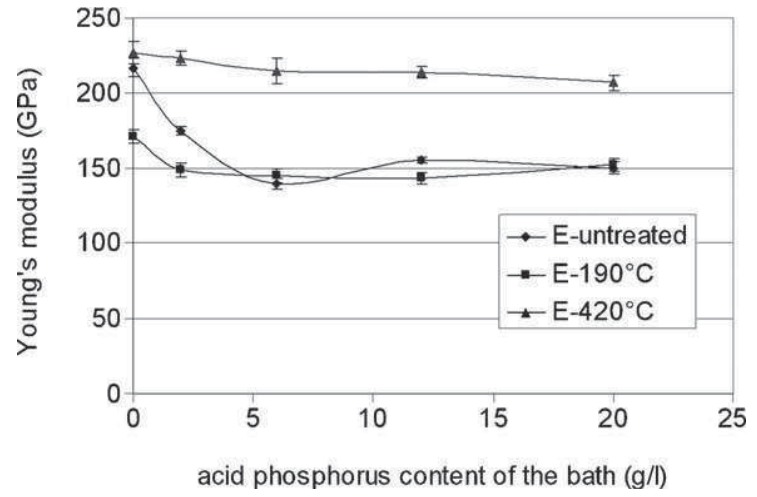

Fig. 16. Effect of heat treatments on the Young's modulus of the deposits: heat treatment at $190^{\circ} \mathrm{C}$ under air and heat treatment at $420^{\circ} \mathrm{C}$ under nitrogen.

\subsection{Influence of the heat treatments}

The study of the NiP-SiC deposits, after a $190^{\circ} \mathrm{C}$ heat treatment for $3 \mathrm{~h}$ in air, highlights no change of topography or morphology compared to the untreated coatings. According to the X-ray phase's analyses, P2S20 and P6S20 deposits are microcrystalline; their hardness increases by $150-200 \mathrm{Hv}$ (Fig. 15). This increase is due to stress relaxation. The stress rate of the as plated coating without phosphorus is estimated at $69 \pm 11.3 \mathrm{MPa}$ and $45.4 \pm 7.7 \mathrm{MPa}$ after a $190^{\circ} \mathrm{C}$ heat treatment. Moreover, for this temperature former studies made it possible to highlight hydrogen desorption of the Ni-P deposits according to their structural state [4,17]. On the other hand, amorphous deposits, P12S20 and P20S20, preserve

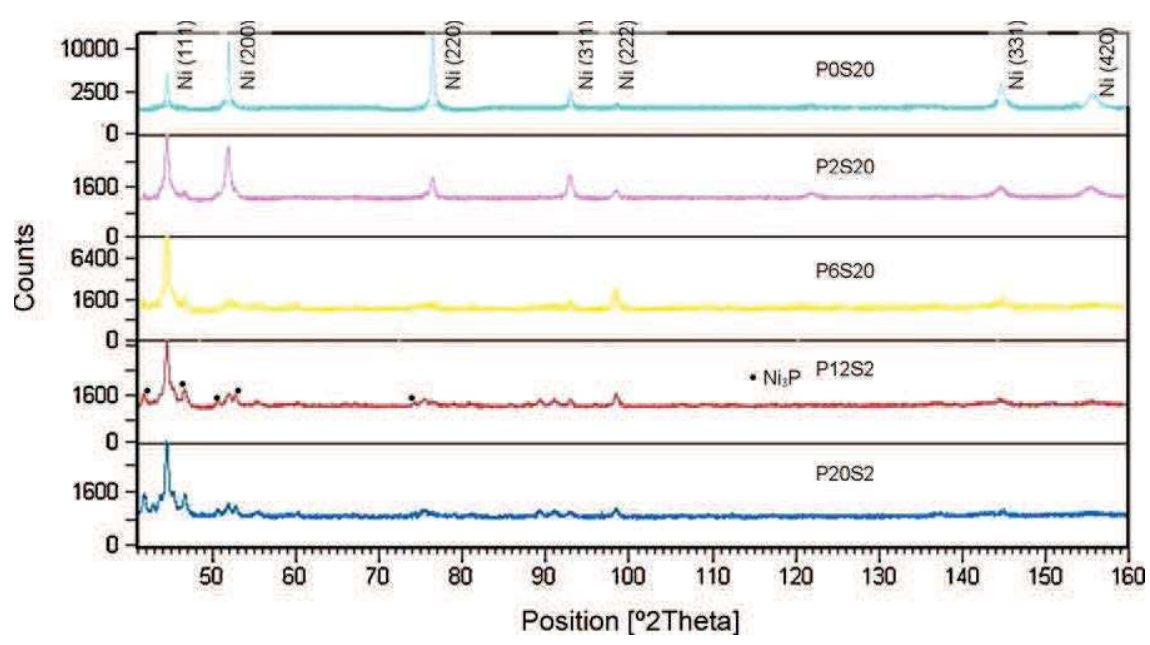

Fig. 17. Effect of heat treatments on the structure. 
Table 3

Effect of heat treatments on the residual stresses.

\begin{tabular}{llc}
\hline Coatings & \multicolumn{2}{l}{ Internal stresses (MPa) } \\
\cline { 2 - 3 } & Average & Standard deviation \\
\hline P0S20 & 54.6 & 8.2 \\
P2S20 & -82.9 & 13.1 \\
P6S20 & -66.5 & 11.7 \\
\hline
\end{tabular}

the same hardness than as-plated deposits. However, after this heat treatment, all the deposits are more fragile. Cracks appear after microhardness tests. These observations are confirmed by nanohardness tests (Fig. 16). No gradient of hardness was observed in the thickness of the deposit whatever its composition.

For a $420^{\circ} \mathrm{C}$ heat treatment of $1 \mathrm{~h}$ in nitrogen, no surface modification was highlighted compared to as-plated samples. However, structural changes appear in the deposits (Fig. 17). These give a more stable structure from a thermodynamic point of view. Indeed, as we can see it on the diffraction X-ray diagrams, all the deposits become crystalline again or microcrystalline. Moreover, precipitation of the $\mathrm{Ni}_{3} \mathrm{P}$ phase is observed [18-20]. However, this is associated with a very important hardening, in particular for the deposits which were amorphous until then. Thus, an increase in the microhardness (Fig. 15) and nanohardness (Fig. 16) of deposits P12S20 and P20S20 are recorded compared to their untreated state of development. This increase of $500 \mathrm{Hv}$ comes primarily from the presence of the precipitates which distort the network and cause it to become crystalline. We find then that the values of hardness generally agree with the literature [18]. The beginning of the decrease in hardness of the treated P20S20 $420^{\circ} \mathrm{C}$ comes from the all important phosphorus content: the $\mathrm{Ni}_{3} \mathrm{P}$ phase tends to form larger aggregates which lose their hardening effect. According to Apachitei et al. [18], a spheroidisation of the precipitates can appear, decreasing by the same their hardening effect.

The calculation of the stress state highlights that the deposits are in a state of compression (Table 3 ). This compression of the matrix is related to the presence of precipitates. The value of the Young's modulus (Fig. 16) increases which once more confirms the return to the crystalline state of these deposits.

\section{Conclusion}

This study made it possible to show the small influence of the insertion of $\mathrm{SiC}$ particles on the morphology and the structure of the deposits with a nickel-phosphorus matrix. The coatings have a $\langle 110\rangle$ fibre texture independent of that of the substrate and of SiC particles content. We notice a slight increase in the microhardness of the deposits with the insertion of $\mathrm{SiC}$ which can be due to the slight reduction in the grain size and to the increased hardness of the $\mathrm{SiC}$ particles.

On the other hand, the insertion of phosphorus severely modifies the morphology of the deposits. The grains of pyramidal form become globular with the insertion of phosphorus. These modifications are closely related to the structural variations. Indeed, measurements of X-ray diffraction highlighted an amorphisation of the deposits for the baths whose phosphorus acid content is higher or equal to $6 \mathrm{gl}^{-1}$. Consequently, the microhardness also evolves with the insertion of phosphorus. It is maximum for the microcrystalline deposits and decreases slightly for the amorphous deposits. The nanoindentation tests confirm not only the evolution of hardness but make also possible to obtain the evolution of the Young modulus according to the inserted phosphorus content. The amorphisation of the coatings results in a fall of the Young modulus.

The post heat treatment at $190^{\circ} \mathrm{C}$ involves a slight increase in hardness which can be correlated to a reduction in the residual tensile stresses. Preceding studies showed a hydrogen desorption for these same deposits at this temperature. The $420^{\circ} \mathrm{C}$ treatment allows a return to a much more stable structure. A nickel phosphide precipitation appears, involving a setting in compression of the nickel matrix and by the same process, a significant increase in hardness.

Future research for this study is to look further into our knowledge on the interface particles stamp and to lead, if possible, the same work by using nanometric particles to try to have a "precipitate-matrix" type hardening effect by blocking the propagation of dislocations.

\section{Acknowledgement}

This study received the financial support of the "Conseil Régional de Midi Pyrénées" under the project heading "multipurpose composite Coatings for the industry of transport".

\section{References}

[1] O. Berkh, S. Eskin, J. Zahavi, Metal Finishing 94 (3) (1996) 35-36.

[2] C. Dedeloudis, M.K. Kaisheva, N. Muleshkov, T. Muleshkov, P. Novak, J. Fransier, J.P. Celis, Plating and Surface Finishing 86 (8) (1999) 57-60.

[3] M. Srivastava, V.K. William Grips, K.S. Rajam, Applied Surface Science 253 (2007) 3814-3824.

[4] S. Vaillant, Thesis of Université Paul Sabatier de Toulouse, France, 2002.

[5] C.K. Chen, H.M. Feng, H.C. Lin, M.H. Hon, Thin Solid Films 416 (1-2) (2002) 31-37.

[6] A. Bai, C. Hu, Materials Chemistry and Physics 79 (1) (2003) 49-57.

[7] W.C. Oliver, G.M. Pharr, Journal of Materials Research 7 (6) (1992) 1564-1583.

[8] M.-C. Chou, M.-D. Ger, S.-T. Ke, Y.-R. Huang, S.-T. Wu, Materials Chemistry and Physics 92 (2005) 146-151.

[9] L. Casteix, J.L. Lebrun, G. Maeder, J.M. Sprauel, Publications Scientifiques et Techniques, ENSAM, 1981.

[10] D.B. Lewis, G.W. Marshall, Surface and Coatings Technology 76 (1996) 150 156.

[11] W. Yucheng, L. Guanghaï, Z. Lide, Y. Bo, Zeitschrift fur metallkunde 91 (9) (2000) 788-793.

[12] D.H. Cheng, W.Y. Xu, L.Q. Hua, Z.Y. Zhang, X.Y. Wang, Plating and Surface Finishing 2 (1998) 85-93.

[13] I. Apachitei, J. Duszczyk, L. Katgerman, P.J.B. Overkamp, Scripta Materialia 38 (9) (1998) 1347-1353.

[14] D. Weaire, M.F. Ashby, J. Logan, M.J. Weins, Acta Metallurgica 19 (1971) 779-788.

[15] H.U. Kunzi, Topics Applied Physics 53 (1983) 169-216.

[16] S. Kobayashi, K. Maeda, S. Takeuchi, Acta Metallurgica 28 (1980) 1641.

[17] A. Leon, H. Staia, E. Hintermann, Surface and Coatings Technology 108-109 (1998) 461-465.

[18] I. Apachitei, F.D. Tichelaar, J. Duszczyk, L. Katgerman, Surface and Coatings Technology 149 (2002) 263-278.

[19] K.G. Keong, W. Sha, S. Malinov, Journal of Alloys and Compounds 334 (2002) 192-199.

[20] M.H. Staia, E.S. Puchi, G. Castro, F.O. Ramirez, D.B. Lewis, Thin Solid Films 355-356 (1999) 472-479. 